\title{
A genetic study of retinopathy in South Indian Type 2 (non-insulin-dependent) diabetic patients
}

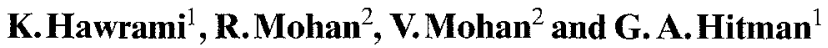 \\ ' Medical Unit, The Royal London Hospital, Whitechapel, London, UK, and \\ ${ }^{2}$ Madras Diabetes Eye Research Centre, Royapuram, Madras, India
}

\begin{abstract}
Summary. Genetic marker studies in diabetic retinopathy are controversial and frequently complicated by possible independent associations of Type 1 (insulin-dependent) diabetes mellitus with the markers so far analysed. We have looked for associations of candidate genes with retinopathy in South Indian Type 2 (non-insulin-dependent) diabetic patients; patients were subdivided into those with exudative maculopathy $(n=53)$, proliferative retinopathy $(n=40)$ and patients free from diabetic retinopathy with a minimum disease duration of 15 years $(n=45)$. DNA was extracted from blood samples and studied by Southern blot hybridisation techniques and the following probe enzyme combinations: HLA-DQB1; Taq 1, HLA-DQA1; Taq 1, HLA-DRA; $\mathrm{Bgl} \mathrm{II}$, insulin gene hypervariable region; Pvu II and the switch region of the immunoglobulin IgM heavy chain gene $(\mathrm{S} \mu)$; Sac I. Differences in genotype distributions between
\end{abstract}

the study groups were only detected with the $S \mu$ probe which detects polymorphism of both $S \mu$ and $S \alpha 1$ (the switch region of $\operatorname{IgA}$ ). Two alleles of So1 were detected sized 7.4 kilobase and 6.9 kilobase. The frequency of 6.9 kilobase homozygotes was lower in proliferative retinopathy $(19 \%)$ compared to patients free from diabetic retinopathy $(54 \%, p=0.005)$ and exudative maculopathy $(46 \%, p=0.03)$. This data suggests that there is a genetic predisposition to proliferative retinopathy in Type 2 (non-insulin-dependent) diabetes of South Indian origin and that this is determined by polymorphism of the heavy chain immunoglobulin genes located on chromosome 14

Key words: Retinopathy, Type 2 (non-insulin-dependent) diabetes mellitus, genetic markers, immunoglobulin genes.
Lack of glycaemic control is an important predictor of diabetic retinopathy [1]. However, this alone is not sufficient to account for the variation in the occurrence of retinopathy, which may be absent from patients with poor glycaemic control over a long period, while others will develop retinopathy despite good diabetic control [2]. Both Type 1 (insulin-dependent) diabetes mellitus and Type 2 (non-insulin-dependent) diabetes mellitus have been shown to have a strong genetic component [3]. Evidence also shows that there is a genetic component to the complications of diabetes, including diabetic retinopathy [4]. Thus, in monozygotic twins with Type 2 diabetes, retinopathy is more frequent and more severe within concordant twin pairs than discordant twins [5].

A major histocompatibility complex (MHC) association with retinopathy has been noted in Type 1 diabetes [4] where a high frequency of DR4 [6], and the fourth component of complement (C4B3) [7] is associated with retinopathy. Additionally, an association of Type 1 diabetic patients with retinopathy has been noted with allotypes of the immunoglobulin heavy chain gene (Gm types) [8].
However, these observations are complicated by possible independent associations of Type 1 diabetes with these markers [9]. As retinopathy is common to both Type 2 and Type 1 diabetes a better group in which to study these associations might be Type 2 diabetic patients with retinopathy, since in Type 2 diabetes there have been no major associations noted with polymorphism of obvious candidate genes so far. In contrast to most previous studies, we have also subdivided our patients into those with either a predominantly exudative or proliferative retinopathy.

\section{Subjects and methods}

\section{Study subjects}

All patients were unrelated Type 2 diabetic patients living in South India and attending the Diabetes Research Centre. A complete opthalmological examination was performed for all the patients included in the study. Corrected visual acuity was assessed in a darkened room using a standard Snellen's chart with internal illumination. A biomicroscopic examination of the anterior segment 
Table 1. Clinical characteristics of the study population

\begin{tabular}{|c|c|c|c|c|c|c|c|c|c|c|}
\hline Patients & & $\begin{array}{l}\text { Age } \\
\text { years }\end{array}$ & $\begin{array}{l}\text { DUR } \\
\text { years }\end{array}$ & $\%$ male & $\begin{array}{l}\mathrm{BMI} \\
\mathrm{kg} / \mathrm{m}^{2}\end{array}$ & $\mathrm{HBA}_{1}$ & $\begin{array}{l}\mathrm{CHOL} \\
\mathrm{mmol} / 1\end{array}$ & $\begin{array}{l}\text { TRIG } \\
\mathrm{mmol} / \mathrm{l}\end{array}$ & $\%$ INS & $\begin{array}{l}\text { DOSE } \\
\text { units/day }\end{array}$ \\
\hline LTD & $n=45$ & $62 \pm 7$ & $23 \pm 8$ & $73 \%$ & $24 \pm 4$ & $10.1 \pm 1.3$ & $5.8 \pm 0.9$ & $1.4 \pm 0.7$ & $80 \%$ & $32 \pm 17$ \\
\hline $\mathrm{MAC}$ & $n=53$ & $54 \pm 7$ & $14 \pm 8$ & $58 \%$ & $24 \pm 6$ & $10.7 \pm 1.5$ & $5.9 \pm 0.8$ & $1.4 \pm 0.8$ & $85 \%$ & $34 \pm 14$ \\
\hline
\end{tabular}

Age $=$ Age at time of study; $\mathrm{BMI}=$ Body mass index; $\mathrm{CHOL}=$ Cholesterol on first attendance at clinic; \% INS: Percentage of patients treated with insulin; LTD = Long-term diabetic patients; $\mathrm{MAC}=$ Exudative maculopathy; $\mathrm{PR}=$ Proliferative retinopathy; DUR $=\mathrm{Duration}$ of diabetes; $\mathrm{HBA}_{1}=$ Glycosylated haemoglobin; TRIG = Triglycerides on first attendance at clinic $;$ DOSE = Dose of insulin

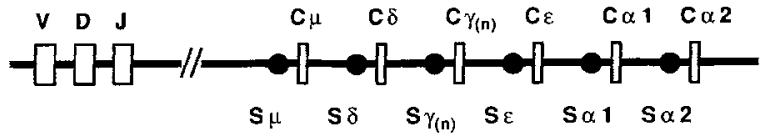

Fig. 1. Heavy chain immunoglobulin gene map (chromosome 14). This is a schematic map and not drawn to scale. V, D, $\mathbf{J}=$ Variable, Diversity and Joining genes; upper laps = heavy chain constant genes denoted by a rectangle; laps $=$ switch region denoted by a filled - in circle; $\mu=\operatorname{IgM} ; \delta=\operatorname{IgD} ; \gamma=\operatorname{IgG} ; \varepsilon=\operatorname{IgE} ; \alpha=\operatorname{IgA} ; n=$ there are $4 \mathrm{IgG}$ genes numbered 1 to 4

was done and the intraocular pressure was recorded. A detailed examination of the fundus was done by direct and indirect ophthalmoscopy. Stereoscopic colour photographs of the seven standard fields were done in all study subjects. Fundus fluorescein angiography was performed in all patients with maculopathy and proliferative retinopathy. The grading of retinal findings was done by a retinal specialist (RM) using an adaptation of the modified Airlie House classification of diabetic retinopathy [10]. Type 2 diabetes was diagnosed by an insidious onset of disease, no insulin treatment within five years of diagnosis and a normal abdominal $x$-ray (the latter to exclude fibrocalculous pancreatic diabetes). Patients were then subdivided into one of three groups. Clinical characteristics are presented in Table 1 . The study was approved by the Ethical Committee of the Diabetes Research Centre (Madras) and informed consent was obtained from the subjects.

Long-term diabetic patients (LTD). Forty-five patients were recruited with a minimum duration of diabetes of 15 years and without evidence of retinopathy clinically as outlined above.

Exudative maculopathy (MAC). Fifty-three patients were recruited with exudative maculopathy. This condition was diagnosed if there was evidence of circinate or scattered exudates, plaques in the macular region with or without thickening of the retina.

Proliferative retinopathy $(P R)$. Forty patients were recruited with proliferative retinopathy. This was diagnosed when there was evidence of new vessel formation on the disc or in any of the quadrants of the retina.

\section{Methods}

DNA was extracted from $10 \mathrm{ml}$ blood samples and studied by Southern blot hybridisation methods [11]. The probes used were cDNA DQB1 [12], cDNA DRA [13], genomic DQA1 [14], a hypervariable region of the cDNA human insulin gene (pHINS 310) [15], and a DNA probe homologous to the switch region of $\operatorname{IgM}(\mathrm{S} \mu)[16]$. The enzymes used were Taq 1 (DQA1, DQA2, DQB1), Bgl II (DRA), PvuII (insulin gene) and Sac 1 (immunoglobulin heavy chain switch region $\mathrm{S} \mu$ ).

\section{Statistical analysis}

Initial comparisons by Chi square analysis were made for differences in either genotypic or allelic frequencies between all three study groups. If a positive result was found further comparisons were then made and the $p$-value corrected for the number of alleles tested.

\section{Results \\ $D Q B 1$ restriction fragment length polymorphisms (RFLPS)}

Using Taq 1 enzyme, two non-allelic DQB1 fragments sizes 2 kilobase (kb) (T2) and $6 \mathrm{~kb}$ (T6) were identified, which have previously been reported to closely associate with DR4 $[17,18]$ and in South Indians mark susceptibility to Type 1 diabetes [19]. The results were not significantly different between subject groups (Table 2).

\section{$D Q A 1 / D Q A 2$ RFLP'S}

Using the restriction enzyme Taq 1, five allelic DQA1 gene fragments were detected. These were sized 6.8, 6.2, $5.5,4.6$ and $2.6 \mathrm{~kb}$ [11]. Two allelic DQA2 (DX $\alpha)$ fragments sized $2.1 \mathrm{~kb}$ and $1.9 \mathrm{~kb}$ were also detected [11]. No differences were found between the clinical groups for either DQA1 (Table 3) or DQA2 (Table 4) allelic frequencies.

Table 2. HLA-DQB1 RFLPs in Type 2 (non-insulin-dependent) diabetic patients with and without retinopathy

\begin{tabular}{lllrrrr}
\hline Patients & Number & \multicolumn{3}{l}{ DQB1 RFLP frequencies } \\
\cline { 2 - 6 } & & \multicolumn{4}{l}{$\mathrm{T} 2+/ \mathrm{T} 6+\mathrm{T} 2+/ \mathrm{T} 6-\mathrm{T} 2-/ \mathrm{T} 6+\mathrm{T} 2-/ \mathrm{T} 6-$} \\
\hline LTD & 39 & $28 \%$ & $13 \%$ & $33.5 \%$ & $25.5 \%$ \\
MAC & 46 & $35 \%$ & $6.5 \%$ & $30.5 \%$ & $28 \%$ \\
PR & 40 & $27.5 \%$ & $10 \%$ & $22.5 \%$ & $40 \%$ \\
\hline
\end{tabular}

$\overline{\mathrm{T}} 2$ and $\mathrm{T} 6+$ (presence) or - (absence) refer to two Taq I DQB1 gene related fragments. We have previously shown that the presence of the T2 fragment strongly associates with Type 1 (insulin-dependent) diabetic patients in this ethnic group identifying DR4-DQw8. The $T 6$ fragment may relate to a DQB2 allele identified because of cross-hybridization with the DQB1 gene probe. RFLP = restriction fragment length polymorphis

LTD = Long-term diabetic patients with no retinopathy; $\mathrm{MAC}=$ Exudative maculopathy; $\mathrm{PR}=$ Proliferative retinopathy $4 \times 3 \mathrm{CHI}$ SQUARE $=3.7 ; p=0.7$

Table 3. HLA-DQA1 allelic frequencies in Type 2 (non-insulin-dependent) diabetic patients with and without retinopathy

\begin{tabular}{lllllll}
\hline Patients & Number & DQA1 allelic frequency \\
\cline { 2 - 7 } & $6.8 \mathrm{~kb}$ & $6.2 \mathrm{~kb}$ & $5.5 \mathrm{~kb}$ & $4.6 \mathrm{~kb}$ & $2.6 \mathrm{~kb}$ \\
\hline LTD & 42 & 0.20 & 0.19 & 0.27 & 0.07 & 0.26 \\
MAC & 49 & 0.19 & 0.18 & 0.35 & 0.10 & 0.17 \\
PR & 39 & 0.26 & 0.18 & 0.35 & 0.14 & 0.14 \\
\hline LTD = Long-term & diabetic patients with no & retinopathy; \\
MAC = Exudative & maculopathy; PR = Proliferative retinopathy; \\
kb= Kilobase \\
$3 \times 5$ CHI SQUARE $=5.8 ; p=0.7$
\end{tabular}


Table 4. HLA-DQA2 genotype and allelic frequencies in Type 2 (non-insulin-dependent) diabetic patients with and without retinopathy

\begin{tabular}{|c|c|c|c|c|c|c|}
\hline \multirow[t]{2}{*}{ Patients } & \multirow[t]{2}{*}{ Number } & \multicolumn{3}{|c|}{ DQA2 genotype frequency } & \multicolumn{2}{|c|}{ Allelic frequency } \\
\hline & & $2.1 \mathrm{HM}$ & $2.1 / 1.9$ & $1.9 \mathrm{HM}$ & $2.1 \mathrm{~kb}$ & $1.9 \mathrm{~kb}$ \\
\hline $\mathrm{D}$ & 42 & $5 \%$ & $45 \%$ & $50 \%$ & 0.27 & 0.73 \\
\hline $\mathrm{MAC}$ & 49 & $8 \%$ & $41 \%$ & $51 \%$ & 0.29 & 0.71 \\
\hline PR & 39 & $10 \%$ & $40 \%$ & $50 \%$ & 0.30 & 0.70 \\
\hline
\end{tabular}

LTD $=$ Long-term diabetic patients with no retinopathy; $\mathrm{MAC}=$ Exudative maculopathy; $\mathrm{PR}=$ Proliferative retinopathy; $\mathrm{HM}=$ homozygote; $\mathrm{kb}=$ Kilobase

$3 \times 3$ CHI SQUARE $=0.9 ; p=0.9$

Table 5. DRA allelic frequencies in Type 2 (non-insulin-dependent) diabetic patients with and without retinopathy

\begin{tabular}{lllll}
\hline Patients & Number & \multicolumn{3}{l}{ DRA alleles } \\
\cline { 3 - 5 } & & $4.5 \mathrm{~kb}$ & $4.2 \mathrm{~kb}$ & $3.8 \mathrm{~kb}$ \\
\hline LTD & 42 & 0.69 & 0.08 & 0.23 \\
MAC & 51 & 0.71 & 0.11 & 0.19 \\
PR & 35 & 0.67 & 0.10 & 0.23 \\
\hline
\end{tabular}

$\mathrm{LTD}=$ longterm diabetic patients with no retinopathy; $\mathrm{MAC}=\mathrm{Exu}-$ dative maculopathy; $\mathrm{PR}=$ Proliferative retinopathy

$3 \times 3$ CHI SQUARE $=0.85 ; p=0.9$

Table 6. Insulin genotype and allelic frequencies in Type 2 (non-insulin-dependent) diabetic patients with and without retinopathy

\begin{tabular}{lllllllll}
\hline Patients & Number & \multicolumn{3}{c}{ Genotype frequency } & & \multicolumn{2}{c}{ Allelic frequency } \\
\cline { 3 - 5 } & & 1,1 & 1,3 & 3,3 & & Class 1 & Class 3 \\
\hline LTD & 42 & $78.5 \%$ & 12 & $\%$ & $9.5 \%$ & & 0.84 & 0.16 \\
MAC & 47 & $78.5 \%$ & 13 & $\%$ & $8.5 \%$ & & 0.85 & 0.15 \\
PR & 37 & $75.5 \%$ & $21.5 \%$ & 3 & $\%$ & & 0.86 & 0.14 \\
\hline
\end{tabular}

LTD $=$ longterm diabetic patients with no retinopathy; MAC $=$ Exudative maculopathy; $\mathrm{PR}=$ Proliferative retinopathy

$3 \times 3$ CHI SQUARE $=2.6 ; p=0.6$

Table 7. Genotype frequency of $S \mu$ and $S \alpha 1$ RFLPs in Type 2 (noninsulin-dependent) diabetic patients with and without retinopathy

\begin{tabular}{lllll}
\hline Patients & Number & \multicolumn{3}{l}{ Su genotypes } \\
\cline { 3 - 5 } & & $2.6 / 2.1$ & $2.6 \mathrm{HM}$ & $2.1 \mathrm{HM}$ \\
\hline LTD & 40 & $47.5 \%$ & $42.5 \%$ & $10 \%$ \\
MAC & 51 & $41 \%$ & $47 \%$ & $12 \%$ \\
PR & 38 & $37 \%$ & $52.5 \%$ & $10.5 \%$ \\
\hline
\end{tabular}

$3 \times 3$ CHI SQUARE $=1.0 ; p=0.9$

\begin{tabular}{lllcl}
\hline Patients & Number & \multicolumn{3}{l}{ S $\alpha 1$ genotypes } \\
\cline { 3 - 5 } & & $7.4 / 6.9$ & $7.4 \mathrm{HM}$ & $6.9 \mathrm{HM}$ \\
\hline LTD & 37 & $38 \%$ & $8 \%$ & $54 \%^{\mathrm{a}}$ \\
MAC & 50 & $38 \%$ & $16 \%$ & $49 \%^{\mathrm{b}}$ \\
PR & 37 & $57 \%$ & $24 \%$ & $19 \%$ \\
\hline
\end{tabular}

$\overline{\mathrm{LTD}}=$ longterm diabetic patients with no retinopathy; MAC $=$ Exudative maculopathy; $\mathrm{PR}=$ proliferative retinopathy; $\mathrm{HM}=$ homozygote

$3 \times 3 \mathrm{CHI}$ SQUARE $=11.4 ; p=0.02$

$p$-value corrected for the number of alleles $=0.04$

a LTD vs PR; CHI SQUARE $=10.65 ; p=0.005$

$p$-value corrected for the number of alleles $=0.01$

${ }^{b} \mathrm{PR}$ vs MAC; CHI SQUARE $=6.9 ; p=0.03$

$p$-value corrected for the number of alleles $=0.06$

\section{DRA RFLPS}

Using the restriction enzyme $\mathrm{Bgl} \mathrm{II}$, three allelic fragments were identified sized 4.5, 4.2 and $3.8 \mathrm{~kb}$ [11]. No differences in allelic frequencies were found between clinical groups (Table 5).

\section{Insulin gene RFLPS}

Two main classes of alleles of the hypervariable polymorphism were identified and designated Class $1(0-$ 600 base-pairs) or Class 3 (1600-2400 base-pairs) according to their size [15]. All the individuals were either homozygous for the Class 1 allele $(1,1)$, homozygous for the Class 3 allele $(3,3)$ or heterozygous $(1,3)$. No significant differences in insulin genotype frequencies were observed between clinical groups (Table 6).

\section{Immunoglobulin heavy chain RFLPS}

Using the restriction enzyme Sac 1, two allelic fragments were detected at the $\mathrm{S} \mu$ locus sized 2.1 and $2.6 \mathrm{~kb}$ while at the So1 locus allelic fragments of 7.4 and $6.9 \mathrm{~kb}$ were found [20]. The genotypic frequencies for $S \alpha 1$ of Type 2 diabetic subjects with proliferative retinopathy were significantly different from those subjects with either exudative maculopathy $(p=0.03)$ or no retinopathy ( $p=0.005)$ (Table 7).

\section{Discussion}

Reports of MHC associations with retinopathy in Type 1 diabetes are controversial. In some studies increased frequencies of HLA-B8, HLA-B15, HLA-B18, DR3/DR4 $[6,21,22]$ and C4B3 [7] have been observed. However, these findings are not always consistent; for instance Barbosa and colleagues only found a decreased frequency of HLA-B7 [23].

In our study of Type 2 diabetic subjects we could not find any significant differences in frequency distribution of DQB1, DQA1, DQA2 or DRA alleles between diabetic patients with or without retinopathy. This probably excludes an association between Type 2 diabetic patients with retinopathy and the Class II region of MHC.

An increased frequency of the Class 3 allele of the insulin gene hypervariable region in South Indian subjects with Type 2 diabetes has been previously reported [19], although this finding is not necessarily consistent in other ethnic groups [9]. One possibility of explaining these discrepancies is if the class 3 allele association is not with the disease per se, but with a complication of Type 2 diabetes such as retinopathy. As no differences were found for insulin genotypes between the subjects with and without retinopathy it would exclude this possibility in this ethnic group.

An immunoglobulin heavy chain $(\mathrm{Gm})$ association with retinopathy has also been noted in Type 1 diabetes [8], as well as between $\mathrm{Gm}$ allogenotypes and insulin anti- 
bodies [24]. The latter observation is of interest as patients with retinopathy have been found to have a high titre of these antibodies [25]. In one previous study of British Caucasoid Type 2 diabetic subjects, differences in distribution of $\mathrm{Gm}$ allogenotypes were found between patients with and without retinopathy [26], although patients were not further subdivided according to the type of retinopathy as in our study. In the South Indians we have found that an allelic variant for the switch region of the IgA heavy chain $(S \alpha 1)$ gene is associated with protection from proliferative retinopathy whereas no such association was found for the switch region of the $\operatorname{Ig} M$ heavy chain gene $(S \mu)$. The immunoglobulin heavy chain genes are located on chromosome 14 and the gene order is depicted in the Figure1. As no association was found with alleles of the switch region of $\operatorname{IgM}$ but an association has been observed with IgG in British Caucasoids and the switch region of IgA in South Indians, it raises the possibility that the gene(s) involved in susceptibility to diabetic retinopathy are located in the $\mathrm{IgG} / \mathrm{IgA}$ chromosomal region, rather than the variable, diversity and joining gene region. Whether the primary association is with the heavy chain genes or adjacent loci can only be deduced from family studies or the demonstration of a tight association of the immunoglobulin genes with an immunoglobulin abnormality of aetiological significance in retinopathy.

Acknowledgement. This study was supported in part by The Wellcome Trust, UK, by a grant given to the Madras Centre.

\section{References}

1. Eschwege E, Job D, Guyot-Argenton C, Aubry JP, Tchobroutsky $G$ (1979) Delayed progression of diabetic retinopathy by divided insulin administration: further follow-up. Diabetologia 16: $13-15$

2. Tchobroutsky G (1978) Relation of diabetic control to development of microvascular complication. Diabetologia 15: 143-152

3. Barnett AH, Eff C, Leslie RDG, Pyke DA (1981) Diabetes in identical twins. Diabetologia 20:87-93

4. Mijovic C, Barnett AH (1987) Immunogenetics of diabetic microangiopathy. In: Barnett AH (ed) Immunogenetics of insulin dependent diabetes. MTP Press, USA, pp 111-120

5. Pyke DA, Tattersall RB (1973) Diabetic retinopathy in identical twins. Diabetes 22: 613-618

6. Dornan TL, Ting A, McPherson CK, Peckar CO, Mann JI, Turner RC, Morris PJ (1982) Genetic susceptibility to the development of retinopathy in insulin dependent diabetes. Diabetes 31 : 226-231

7. Mijovic C, Fletcher J, Bradwell AR, Harvey T, Barnett AH (1985) Relation of gene expression (allotype) of the fourth component of complement to insulin dependent diabetes and its microangiopathic complications. Br Med J 291: 9-10

8. Mijovic C, Fletcher JA, Bradwell AR, Barnett AH (1986) Phenotypes of the heavy chains of immunoglobulin in patients with diabetic microangiopathy: evidence for an immunogenetic predisposition. Br Med J 292: 433-435

9. Hitman GA, Niven MJ (1989) Genes and diabetes mellitus. Br Med Bull 45: 191-205

10. Diabetic Retinopathy Study Research Group (1981) Report 7. A modification of the Airlie House classification of diabetic retinopathy. Invest Ophthalmol Vis Sci 21:210-226
11. Hitman GA, Niven MJ, Festenstein H, et al. (1987) HLA Class II alpha chain gene polymorphisms in patients with insulin dependent diabetes mellitus, dermatitis herpetiformis and coeliac disease. J Clin Invest 79: 609-615

12. Larhammar D, Schenning L, Gustafsson K, Winman K, Claesson L, Rask L, Peterson PA (1982) Complete amino acid sequence of an HLA-DR antigen like B chain as predicted from the nucleotide sequence: similarities with immunoglobulins and HLA-A, -B, -C antigens. Proc Natl Acad Sci USA 79: 3687-3691

13. Larhammar D, Gustafsson K, Claesson L, et al. (1982) Alpha chain of HLA-DR transplantation antigen is a member of the same protein super family as the immunoglobulins. Cell 30 : $153-161$

14. Spielman RS, Lee J, Bodmer WF, Bodmer JG, Trowsdale J (1984) Six HLA-DR region $\alpha$ chain genes on human chromosome 6: polymorphisms and associations of $\mathrm{DC} \alpha$-related sequences with DR types. Proc Natl Acad Sci USA 81: 3461-3465

15. Bell GI, Horita S, Karam JH (1984) A polymorphic locus near the human insulin gene is associated with insulin dependent diabetes mellitus. Diabetes 33: 176-186

16. Flanagan JG, Rabbitts TH (1982) Arrangement of human immunoglobulin heavy chain constant region genes implies evolutionary duplication of a segment containing $\gamma, \varepsilon$ and $\alpha$ genes. Nature 300: 709-713

17. Sachs JA, Cassell PG, Festenstein H, Awad J, Hitman GA (1987) $D Q \beta$ restriction fragment length polymorphism and its relationship to insulin dependent diabetes mellitus. Dis Markers 5: 199-206

18. Festenstein H, Awad J, Hitman GA et al. (1986) New HLA DNA polymorphisms associated with autoimmune disease. Nature 322: 64-67

19. Kambo PK, Hitman GA, Mohan V, Ramachandran A, et al. (1989) The genetic predisposition to fibrocalculous pancreatic diabetes. Diabetologia 32: 45-49

20. Millward BA, Hitman GA, Cassell PG, Sachs JA, Welsh KI, Demaine AG (1988) Immunoglobulin heavy chain switch region polymorphisms are not associated with type 1 diabetes. Diab Med 5: 543-546

21. Larkins RG, Martin FIR, Tait BD (1978) HLA patterns and diabetic retinopathy. Br Med J 1: 1111

22. Standl E, Dexel T, Lander T, Albert ED, Scholz S (1980) HLA antigens and diabetic retinopathy: a different view warranted. Diabetologia 18: 79-80

23. Barbosa J, Saner B (1984) Do genetic factors play a role in pathogenesis of diabetic microangiopathy. Diabetologia 27 : $487-492$

24. Nakio Y, Matsumoto H, Mijazaki T, et al. (1981) IgG heavy chain $(\mathrm{Gm})$ allotypes and immune response to insulin in insulin requiring diabetes mellitus. N Engl J Med 304: 407-409

25. Anderson OO (1976) Anti-insulin antibodies and late diabetic complications. Acta Endocrinol 83:329-340

26. Baldwin RN, Mijovic C, Fletcher J, Bradwell AR, Barnett $\mathrm{AH}$, Hockaday TDR (1988) Immunoglobulin heavy chain phenotypes and background retinopathy in non-insulin dependent diabetes. Br Med J 297: 1104-1105

Received: 2 January 1991

and in revised form: 14 February 1991

Dr. G.A.Hitman

Medical Unit

The Royal London Hospital

Whitechapel

London E1 1BB

UK 